\title{
Resistance Spot Welding of dissimilar Steels
}

\author{
Ladislav Kolařík $^{1}$, Miroslav Sahul ${ }^{2}$, Marie Kolaříková ${ }^{1}$, \\ Martin Sahul $^{3}$, Milan Turňa ${ }^{2}$, Michal Felix ${ }^{4}$ \\ ${ }^{1}$ Czech Technical University in Prague, Department of Manufacturing Technology, \\ Technická 4, 16607 Praha, Czech Republic \\ ${ }^{2}$ Slovak University of Technology, Department of Welding, Paulinska 16, 91724 Trnava, Slovak Republic \\ ${ }^{3}$ Slovak University of Technology, Department of Materials Engineering, Paulinska 16, 91724 Trnava, Slovak Republic \\ ${ }^{4}$ Fronius Česká republika, s.r.o, Dolnoměcholupská 1535/14, 10200 Praha, Czech Republic \\ Correspondence to: Ladislav.Kolarik@fs.cvut.cz
}

\begin{abstract}
This paper presents an analysis of the properties of resistance spot welds between low carbon steel and austenitic CrNi stainless steel. The thickness of the welded dissimilar materials was $2 \mathrm{~mm}$. A DeltaSpot welding gun with a process tape was used for welding the dissimilar steels. Resistance spot welds were produced with various welding parameters (welding currents ranging from 7 to $8 \mathrm{kA}$ ). Light microscopy, microhardness measurements across the welded joints, and EDX analysis were used to evaluate the quality of the resistance spot welds. The results confirm the applicability of DeltaSpot welding for this combination of materials.
\end{abstract}

Keywords: resistance spot welding, welded joint, low carbon steel, austenitic stainless steel.

\section{Introduction}

Several problems arise when welding dissimilar steels, related mainly to the different physical, chemical and mechanical properties of the welded materials. Austenitic stainless steel and low carbon steel possess a good combination of mechanical properties, formability, weldability and resistance to corrosion. This combination of steels is extensively used in the power generation industry $[1,2]$. Research on welding is carried out at various research institutions $[3,4]$. The aim of our paper is to analyze and compare the properties of resistance spot welds of low carbon steel and austenitic stainless steel. Optical microscopy, microhardness measurements and EDX analysis were used to analyse the properties of the spot welded joints.

\section{Experimental}

The welded materials used for resistance spot welding were DC 01 low carbon steel (LCS) and AISI 304 austenitic stainless steel (ASS). The welded steels were $2 \mathrm{~mm}$ thick. Both metals were delivered in cold rolled state. The chemical composition of the steels is given in Tables 1 and 2. It was necessary to take various properties of the welded metals into consideration, e.g. thermal conductivity and electrical resistivity. The thermal conductivity of ASS and LCS is about $16.2 \mathrm{~W} \cdot \mathrm{m}^{-1} \cdot \mathrm{K}^{-1}$ and $52 \mathrm{~W} \cdot \mathrm{m}^{-1} \cdot \mathrm{K}^{-1}$, respectively. Differences in the properties of the metals re- sulted in an asymmetrical weld nugget. The electrical resistivity of ASS is approximately $72 \mu \Omega \cdot \mathrm{cm}$, while the electrical resistivity of LCS is $14.2 \mu \Omega \cdot \mathrm{cm}$ [6].

Table 1: Chemical composition of DC 01 low carbon steel

\begin{tabular}{|c|c|c|c|}
\hline \multicolumn{4}{|c|}{ Main alloying elements [wt. \%] } \\
\hline C & $\mathrm{Mn}$ & $\mathrm{P}$ & $\mathrm{S}$ \\
\hline$\leq 0.12$ & $\leq 0.60$ & $\leq 0.045$ & $\leq 0.045$ \\
\hline
\end{tabular}

Table 2: Chemical composition of AISI 304 austenitic stainless steel

\begin{tabular}{|c|c|}
\hline \multicolumn{2}{|c|}{ Main alloying elements [wt. \%] } \\
\hline $\mathrm{C}$ & $\leq 0.07$ \\
\hline $\mathrm{Cr}$ & 17.0 to 19.5 \\
\hline $\mathrm{Ni}$ & 8.0 to 10.5 \\
\hline $\mathrm{Mn}$ & $\leq 2.00$ \\
\hline $\mathrm{Si}$ & $\leq 0.045$ \\
\hline $\mathrm{P}$ & $\leq 0.045$ \\
\hline $\mathrm{S}$ & $\leq 0.015$ \\
\hline $\mathrm{N}$ & $\leq 0.11$ \\
\hline
\end{tabular}


Resistance spot welds were produced at the Fronius Technology Centre in Prague, in cooperation with the Faculty of Mechanical Engineering, Czech Technical University in Prague. The DeltaSpot system by Fronius was used for producing the resistance spot welds. DeltaSpot is a welding gun (Figure 1) with a running process tape (type PT 3200-CrNi and
PT 1200-steel) that protects the electrodes $(\mathrm{R}+100$ and $\mathrm{R}+500, \oslash 16 \mathrm{~mm}$ ) from wear and deposits of sheet coatings.

The welding current used in the experiment ranged from 7 to $8 \mathrm{kA}$. The other parameters were kept constant. The welding parameters are given in Table 3 .
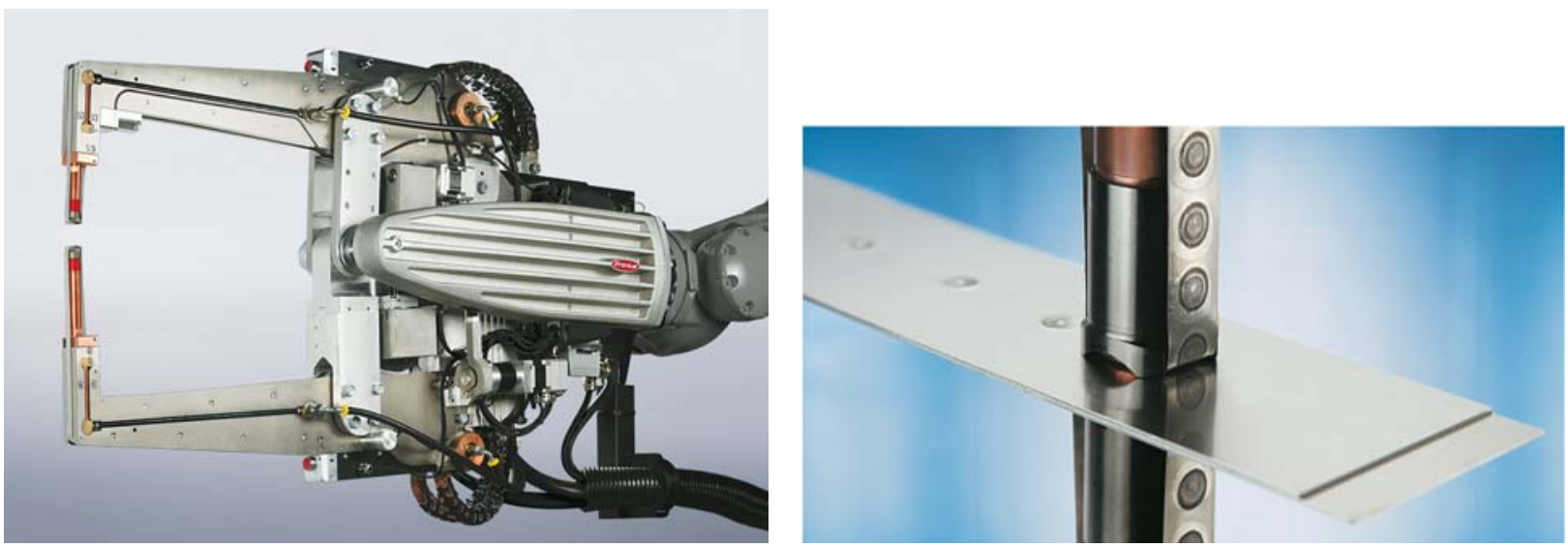

Figure 1: DeltaSpot X-Gun (left) and a detail of the process tapes (right) [5]

Table 3: Parameters for welding dissimilar steels

\begin{tabular}{|c|c|c|c|c|}
\hline Sample code & $\begin{array}{c}\text { Welding } \\
\text { current } \\
{[\mathrm{kA}]}\end{array}$ & $\begin{array}{c}\text { Welding current } \\
\text { cycle duration } \\
{[\mathrm{ms}]}\end{array}$ & Force & $\begin{array}{c}\text { Force cycle } \\
\text { duration [ms] } \\
{[\mathrm{kN}]}\end{array}$ \\
\hline 1 & 8.0 & 370 & $4.0 / 3.4$ & $310 / 480$ \\
\hline 2 & 7.5 & 370 & $4.0 / 3.4$ & $310 / 480$ \\
\hline 3 & 7.0 & 370 & $4.0 / 3.4$ & $310 / 480$ \\
\hline
\end{tabular}

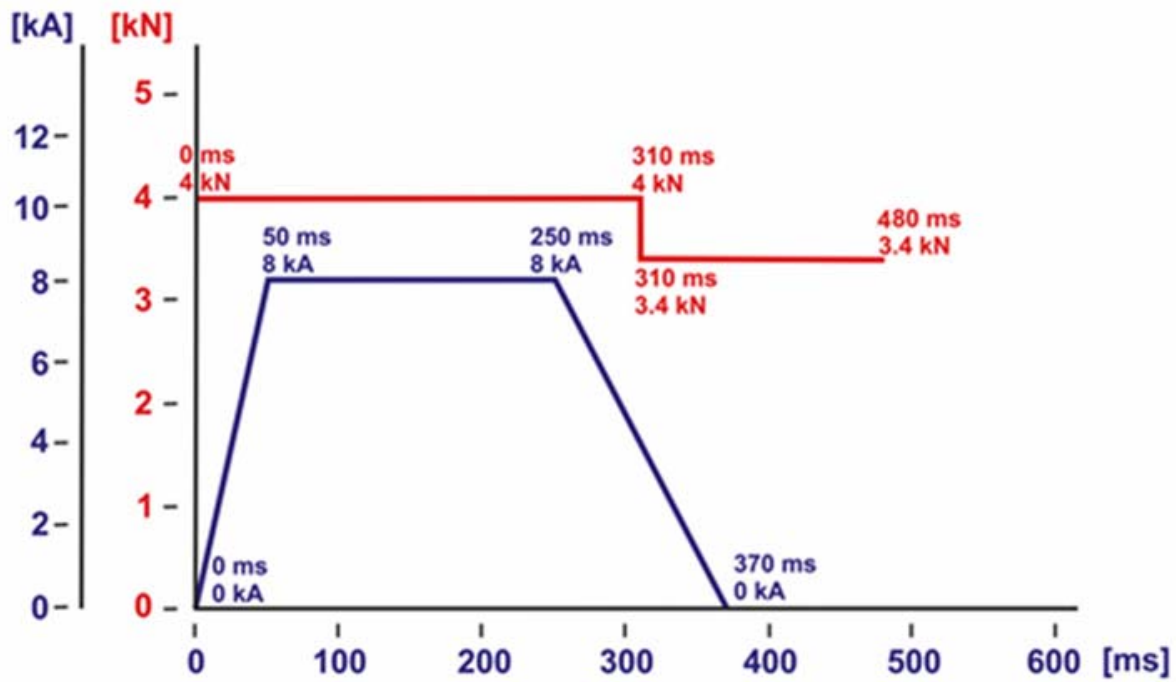

Figure 2: Example of a welding cycle - Dependence of welding current and force on time 

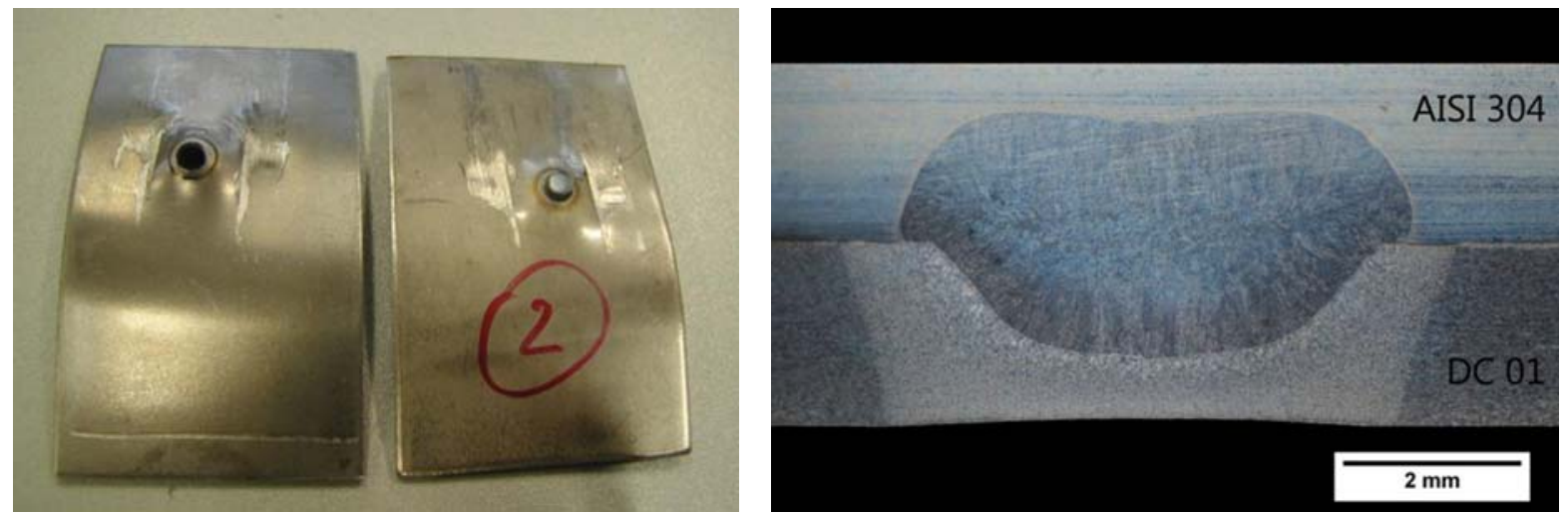

Figure 3: Verification of the weld nugget size (left) and the macrostructure of a selected dissimilar resistance spot weld $\left(I_{W}=7.5 \mathrm{kA}\right)$

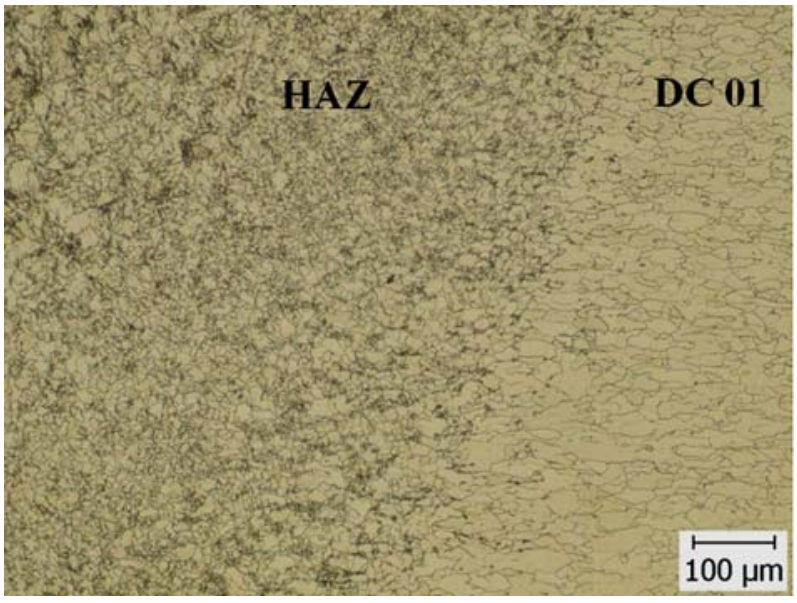

Figure 4: HAZ - DC 01 steel interface

The quality of the weld joins was proved by peel testing (EN ISO 10 447), see Figure 3 - left. The size of the weld nugget was measured. Sample 2 was chosen for further analysis.

Light microscopy (for analysing the macro- and microstructures of the welds), microhardness measurements across the welded joints, and EDX analysis were used to analyse the properties of the resistance spot welds that were produced. The macrostructure of the welded joint produced by using a welding current of $7.5 \mathrm{kA}$ is documented in Figure 3. As the macrostructure suggests, the welded joint is asymmetrical. The fusion zone size on the stainless steel side is larger than the fusion zone on the low carbon steel side. Similar results were also observed in welds produced with welding currents of 7 and $8 \mathrm{kA}$. The heat-affected zone (HAZ) of the DC 01 steel is broader due to the higher thermal conductivity of the low carbon steel sheet. On the basis of macrostructure analysis, it can be stated that the higher the welding current that is used, the larger the fusion zone.

The microstructure of low carbon steel is fully ferritic. Grain refining was observed in the low temper- ature HAZ of carbon steel (Figure 4). Some amounts of pearlite were also present. Grain coarsening occurred in the high temperature HAZ of carbon steel.

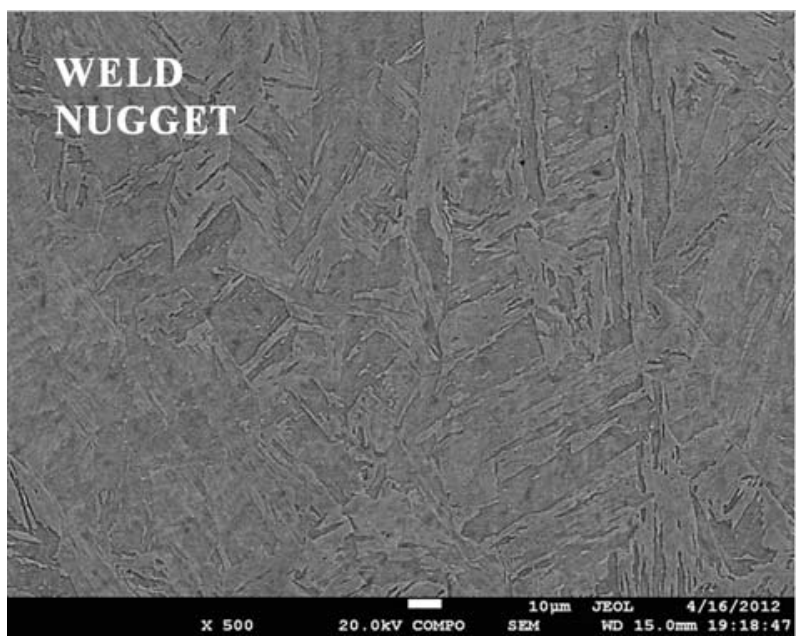

Figure 5: SEM image of a dissimilar steels weld nugget

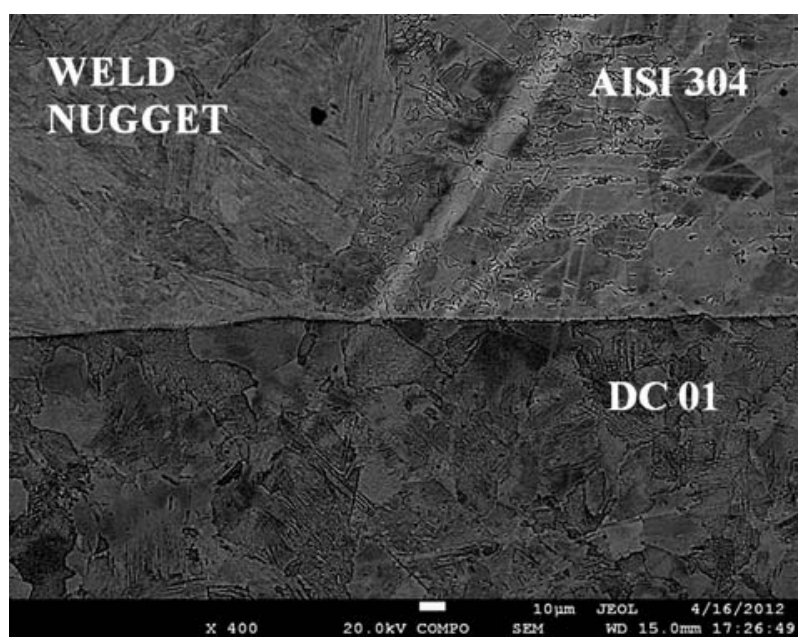

Figure 6: SEM image of base materials and a welded joint 
The structure of the weld nugget obtained by scanning electron microscopy is presented in Figure 6 . A JEOL $7600 \mathrm{~F}$ scanning electron microscope with a field emission gun fitted with an X-Max $50 \mathrm{~mm}^{2}$ EDX detector was used to obtain images and for EDX analysis. The observation parameters were: accelerating voltage $20 \mathrm{keV}$, probe current $2 \mathrm{nA}$ and working distance $15 \mathrm{~mm}$.

A more detailed view of the welded joint produced with a welding current of $8.0 \mathrm{kA}$ is shown in Figure 6 .

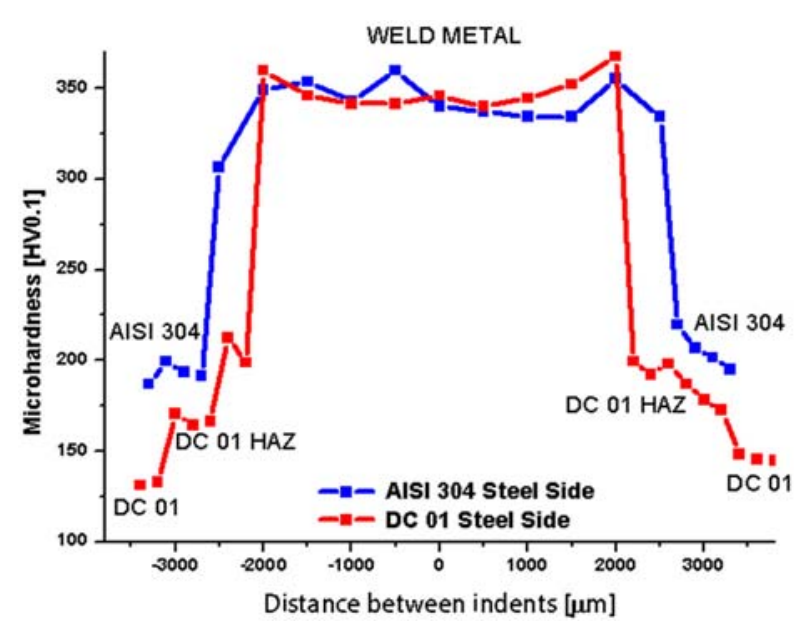

Figure 7: Course of microhardness across a welded joint $\left(I_{W}=7.5 \mathrm{kA}\right)$

Vickers microhardness measurements across the weld nugget were performed on each sample. The individual indents were made horizontally, in two rows (AISI 304 steel and DC 01 steel, respectively). The first one was done in austenitic stainless steel across the weld nugget and the other in low carbon steel through HAZ and the weld nugget. The distance between the indents in the weld metal was $500 \mu \mathrm{m}$. The distance between the indents in the base metals and HAZ was $200 \mu \mathrm{m}$. The loading used in the experimental measurements was $100 \mathrm{~g}$, acting over a period of $10 \mathrm{~s}$. The hardness measurement results are given in Figure 7.

EDX analysis was used for a more detailed study of the welded joint - base metal interface. The area examined by EDX analysis, and also the line profiles of $\mathrm{Cr}, \mathrm{Ni}, \mathrm{Mn}$ and $\mathrm{Fe}$ elements are given in Figure 8.

\section{Conclusion}

The properties of resistance spot welds of dissimilar steels have been studied. The influence of the welding parameters on the weld metal size has been evaluated. The size of the weld metal increases with welding current increase. The HAZ of the low carbon steel sheet was broader than the HAZ of the austenitic stainless steel. This is related to the higher thermal conductivity of DC 01 steel. The structure of low carbon steel is fully ferritic. AISI 304 steel consists of austenitic grains with the presence of twins. Grain refining of ferrite grains was observed in the low temperature HAZ at carbon steel. The hardness increased in the fusion zone. In low carbon steel, the increase was from a value of 131 HV0.1, measured in the base metal, to hardness of 367.9 HV0.1 (measured in the weld metal). A similar perceptible increase was attained in stainless steel sheet. The hardness measured in AISI 304 steel increased from a value of $186.9 \mathrm{HV} 0.1$ to a value of $359.9 \mathrm{HV} 0.1$. A more detailed study of the welded joint interface was performed by EDX analysis. An increase in iron content in the direction from weld metals towards DC 01 steel was observed. However, a decrease in $\mathrm{Cr}, \mathrm{Mn}$ and $\mathrm{Ni}$ from the weld metal towards the DC 01 steel was also recorded.
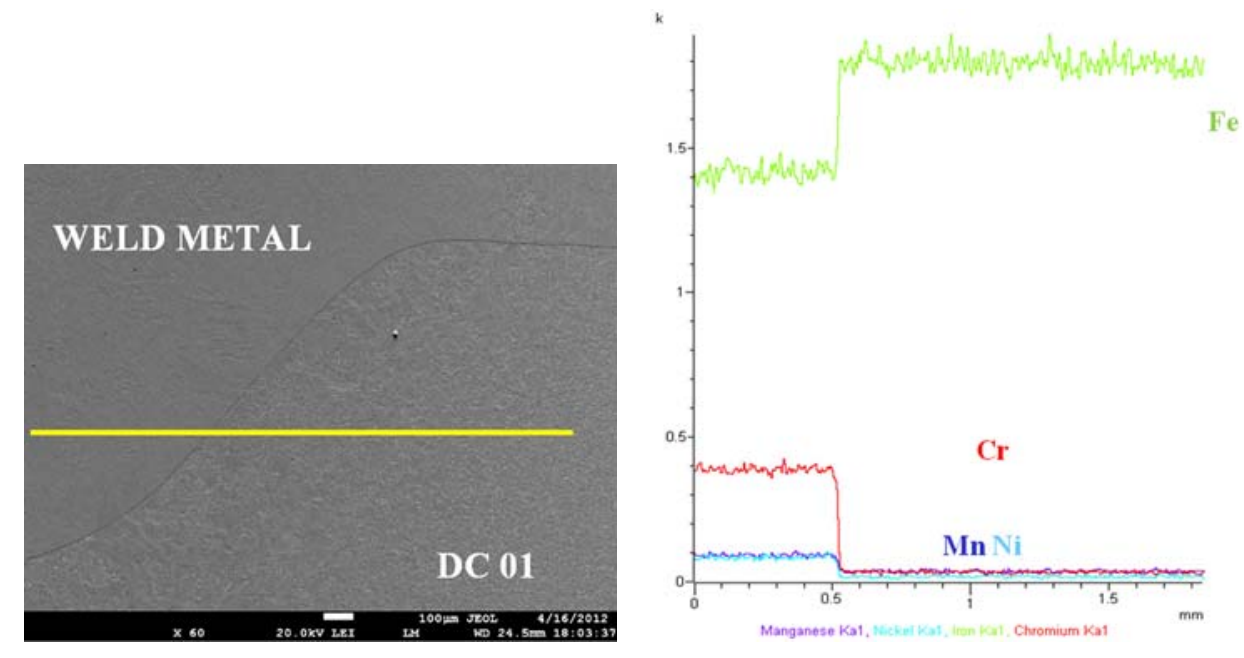

Figure 8: a) Area studied using EDX analysis, b) line profiles of $\mathrm{Cr}, \mathrm{Ni}, \mathrm{Mn}$ and Fe across the weld metal DC 01 steel interface $\left(I_{W}=7.5 \mathrm{kA}\right)$ 


\section{Acknowledgement}

The paper was prepared with support from the Grant Agency of the Ministry of Education, Science, Research and Sport of the Slovak Republic and the Slovak Academy of Sciences within project No. $1 / 2594 / 12$.

The research was financed by the Czech Ministry of Education, Youth and Sport within the framework of project SGS CVUT 2010 - OHK2-038/10.

\section{References}

[1] Arivazhagan, N., Singh, S., Prakash, S., Reddy, G. M.: Investigation on AISI 304 Austenitic Stainless Steel to AISI 4140 Low Alloy Steel Dissimilar Joints by Gas Tungsten Arc, Electron Beam and Friction Welding. In Materials and Design 2011. Elsevier, p. 3036-3050. ISSN 0261-3069.

[2] Krishnaprasad, K., Prakash, R. V.: Fatigue Crack Growth Behavior in Dissimilar Metal Weldment of Stainless Steel and Carbon Steel. In Engineering and Technology, 2009, p. 873-879.
[3] Marashi, P., Pouranvari, M., Amirabdollahian, S., Abedi, A., Goodarzi, M.: Microstructure and Failure Behavior of Dissimilar Resistance Spot Welds between Low Carbon Galvanized and Austenitic Stainless Steels. In Materials Science and Engineering, 2008, Elsevier, p. 175-180. ISSN 0921-5093.

[4] Torkamany, M. J., Sabbaghzadeh, J., Hamedi, M. J.: Effect of Laser Welding Mode on the Microstructure and Mechanical Performance of Dissimilar Laser Spot Welds between Low Carbon and Austenitic Stainless Steels. In Materials and Design, 2012, Elsevier, p. 666-672. ISSN 0261-3069.

[5] DeltaSpot Resistance Welding. In Fronius [online]. 2011 [cit. 2012-03-30]. Available on: http://www.fronius.com/new/deltaspot

[6] Jamasri, Ilman, M. N., Soekrisno, R., Triyono: Corrosion Fatigue Behavior of Resistance Spot Welded Dissimilar Metal Welds between Carbon Steel and Austenitic Stainless Steel with Different Thickness. In Procedia Engineering, 2011, Elsevier, p. 649-654. ISSN 1877-7058. 